\title{
Goldfish Retinal Axons Respond to Position-Specific Properties of Tectal Cell Membranes In Vitro
}

\author{
Jost Vielmetter and Claudia A. O. Stuermer \\ Friedrich-Miescher-Laboratorium \\ der Max-Planck Gescllschaft \\ 7400 Tübingen \\ Federal Republic of Germany
}

\section{Summary}

Using a special in vitro assay, we tested whether retinal ganglion cell axons in an adult vertebrate, the goldfish (which can regenerate a retinotopic projection after optic nerve section), recognize position-specific differences in cell surface membranes of their target, the tectum opticum. On a surface consisting of alternating stripes of membranes from rostral and caudal tectum, temporal axons accumulate on membranes derived from their retinotopically related rostral tectal half. $\mathrm{Na}$ sal axons grow randomly over both types of membranes. Nasal and temporal axons can elongate on both rostral and caudal membranes. A quantitative growth test, however, revealed that caudal membranes are less permissive substrates for the outgrowth of temporal axons than rostral membranes, and than rostral or caudal membranes for nasal axons.

\section{Introduction}

In lower vertebrates the projection of the retinal ganglion cells onto their primary central target, the optic tectum, is retinotopically organized such that the neighborhood relationship of the ganglion cells is maintained in the arrangement of their terminal arbors in tectum. The molecular mechanisms that enable the growing axons to arrive at their appropriate target sites in tectum are still unknown. One theory proposed to explain the formation of patterned connections postulates the existence of spatial markers on retinal axons and tectal cells. The spatial markers are thought to mediate the recognition between the growing axons and cells of their corresponding regions in tectum (Sperry, 1963; Bonhoeffer and Gierer, 1984; Gierer, 1987). Although frequently disputed (reviewed by Purves and Lichtman, 1985), this theory has gained substantial experimental support in recent years (Bonhoeffer and Huf, 1982; Fujisawa et al. 1982; Holt and Harris, 1983; Harris, 1984; Meyer et al. 1985; Fujisawa, 1987; Walter et al., 1987a, 1987b; Stuermer 1988a, 1988b, 1988c).

Using an in vitro assay, Bonhoeffer and colleagues have provided evidence that spatial markers are associated with tectal cell surfaces (Kern-Veits, 1985; Walter et al., 1987a, 1987b). When chick retinal axons of temporal origin were grown on monolayers of tectal cells, they exhibited a specific recognition for cells from their retinotopically appropriate rostral tectum (Bonhoeffer and Hut, 1982). In a recently modified version of this assay, chick retinal axons were confronted with cell membranes of rostral and caudal tectal origin in alternating stripes (Walter et al., 1987a). Here again, temporal axons grew preferentially on the stripes containing membranes of their retinotopically appropriate rostral tectum. In their second paper Walter et al. (1987b) presented results suggesting that the temporal axons accumulated on rostral membranes not because they were specifically attracted by components associated with these membranes, but rather because they were apparently sensitive to a repulsive component associated with caudal membranes. Thus, when given a choice between rostral and caudal mem branes, temporal axons prefer the rostral membranes since they avoid growing on caudal membranes. In the following text, the term "preference of axons" is used to account for the accumulation of axons on one of the membrane stripes without implying that attractive substances are involved in the specific axonal response.

The preferential growth of chick retinal axons on rostral membranes was only seen when the membranes were prepared from embryonic tecta between E6 and E14. This is the time period over which the retinotectal projection develops in the living animal (Crossland et al. 1975). The retinal axons were always obtained from E6 chicken, but the preference of E6 temporal axons for rostral membranes gradually decreased when the tecta became older. This indicates that the expression of the cell surface components sensed by the growing axons declines with increasing embryonic age. Cold-blooded animals, such as amphibians and fish, do not only possess the ability to build a retinotopic projection in embryogenesis, hut are also able to reestablish such a projection in the adult when the optic nerve is sectioned (for review see Gaze, 1970). Provided that regenerating axons are also guided by cytochemical cell surface markers (Sperry, 1963; Gierer, 1981, 1987), these markers should be available not only in the embryo, but also in the adult.

We have previously performed a detailed analysis of the pathways of embryonic, normal adult, and regenerating axons in goldfish (Stuermer and Easter, 1984a, 1984b; Stuermer, 1988a, 1988b, 1988c) and found the mode of axonal growth to be consistent with the concept that target finding is facilitated by positional markers. Based on these evidences, we began to investigate whether regenerating goldfish axons would exhibit a preference for tectal cell membranes in vitro by applying the choice assay developed by Bonhoeffer for the chick (Walter et al., 1987a, 1987b) to goldfish.

We will demonstrate here that temporal axons from adult goldfish accumulate on membranes derived from their retinotopically appropriate rostral tectum when given a choice between rostral and caudal tectal membranes. We further tested whether the two types of tectal membranes differ in their ability to promote the outgrowth of axons from nasal and temporal explants. On rostral membranes no significant difference between the number of axons from temporal and nasal explants is observed. A specific reduction of axonal outgrowth, how 


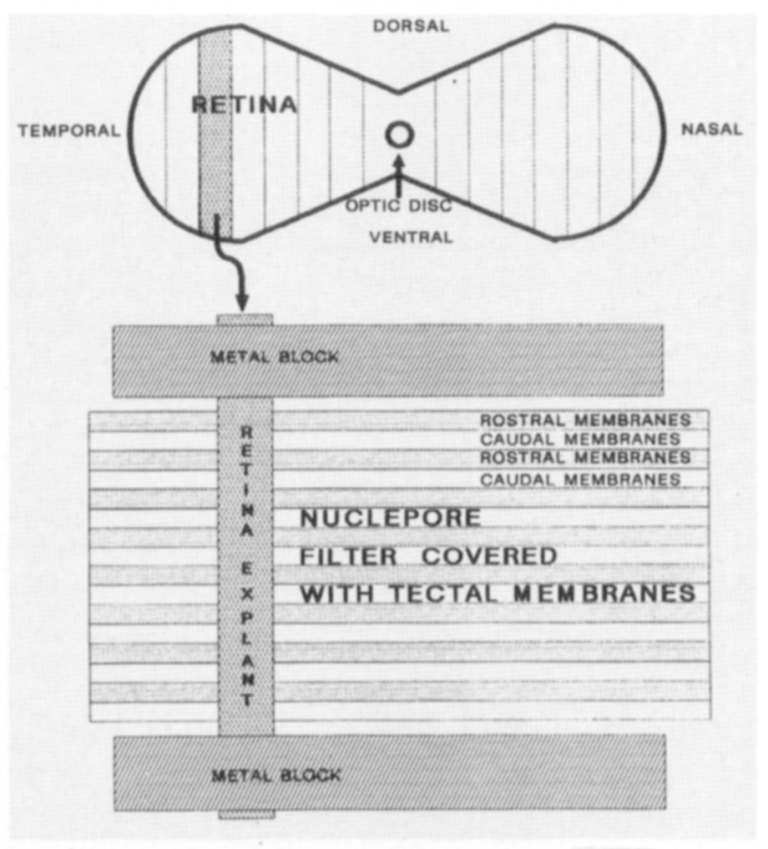

Figure 1. Schematic Representation of the Experimental Design The upper figure shows the isolated and trimmed retina attached to a filter. After discarding the dorsal and ventral parts, the retina and filter were sectioned into segments from the nasal to the temporal pole, as indicated by the dotted lines. Either nasal or temporal segments were used for explantation onto the tectal membrane carpet. The lower figure illustrates schematically the experimental design, which is described in Experimental Procedures.

ever, is found for temporal explants (but not for the nasal explants) when explanted onto caudal membranes.

\section{Results}

In an initial experiment we tested whether retinal axons can grow on tectal membranes attached to a Nucleopore filter support. Only rostral or caudal membranes were applied to separate Nucleopore filters in stripes. The lanes between the membrane stripes were left uncovered. Explants from both nasal and temporal retina extend neurites on both types of membranes. Only a few axons were seen on the plain filter.

\section{Response to Position-Specific Properties on Tectal Cell Membranes by Temporal Axons}

To investigate whether retinal axons have a preference for membranes of their topographically related target region in tectum, nasal and temporal axons were confronted with membranes of rostral and caudal tectal origin in alternating series of parallel stripes (Walter et al., 1987a) (Figure 1). In the first group of experiments, membranes were prepared from tecta of normal, untreated goldfish. When exposed to stripes of caudal and rostral membranes, axons from temporal retina accumulate on stripes of the rostral membranes. One typical example of such an experiment is illustrated in Figure 2a. The beads, which were always mixed with the inembranes applied first, are discernible as light dots and are restricted to the stripes of caudal membranes. As is clearly visible in Figure $2 a$, the vast majority of the axons travel on the unlabeled stripes of rostral membranes. When the order of application is reversed, temporal axons still accumulate on rostral membranes (Figure $2 b$ ). However, the number of axons that grow over caudal membranes is increased.

Membranes that are applied first are slightly contaminated with the membranes being applied second. Our results suggest that a contamination of caudal membranes with rostral membranes does not interfere with the ability of temporal axons to demonstrate a strong preference for rostral membranes. In the reverse case, however, the contamination of rostral membranes with those of caudal origin does appear lo weaken the apparent preference of temporal axons for the rostral membrane stripes (see Discussion).

Nasal axons exposed to rostral and caudal membranes do not show any preference. Instead, they cross random. ly over the membrane carpet (Figure 3). This growth pattern of nasal axons is independent of the order of membrane application.

A quantitative evaluation of this first group of experiments (and of the following two groups to be described below) is presented in histograms in Figure 4. All preparations were scored blindly and categorized according to whether they showed a distinct, moderate, or no preference for one of the membrane stripes. Growth patterns typical for each category are illustrated in Figure 5. A distinct preference for rostral membranes was rated 1 (Figures $5 a$ and $5 b$ ), a moderate preference was rated 2 (Figures $5 \mathrm{c}$ and $5 \mathrm{~d}$ ), and no preference for rostral or caudal membranes was rated 3 (Figures $5 \mathrm{e}$ and $5 f$ ). A distinct and moderate preference for caudal membranes would have been rated 5 and 4 , respectively; however, in none of our experiments did axons accumulate on caudal membranes. Figure 4 illustrates the absolute and relative numbers of preparations falling into one of these categories. Figure $4 \mathrm{~A}$ gives the score for temporal axons when caudal membranes were applied first; Figure $4 B$ gives the score for temporal axons when rostral membranes were applied first. In most preparations of this first group of experiments (represented by open bars in Figures $4 \mathrm{~A}-$ 4D), temporal axons in Figure 4A exhibited a strong preference for rostral membranes; this was true only in onethird of the preparations in Figure 4B. Accordingly, moderate preferences were more frequent in Figure $4 B$ than in Figure 4A. Preparations in which temporal axons had no preference for either of the membrane stripes were rare in Figures $4 \mathrm{~A}$ and $4 \mathrm{~B}$. Cases in which temporal axons would accumulate on caudal membranes were never observed.

Nasal axons did not show a preference for either one of the membrane stripes (Figures $4 \mathrm{C}$ and $4 \mathrm{D}$, open bars).

\section{Lack of Preference of Dorsal and Ventral Axons}

Whether axons from the dorsal or ventral retina might recognize position-specific differences between the dorsal and ventral hemitectum was examined in sets of experiments similar to those described above (49 prepara- 

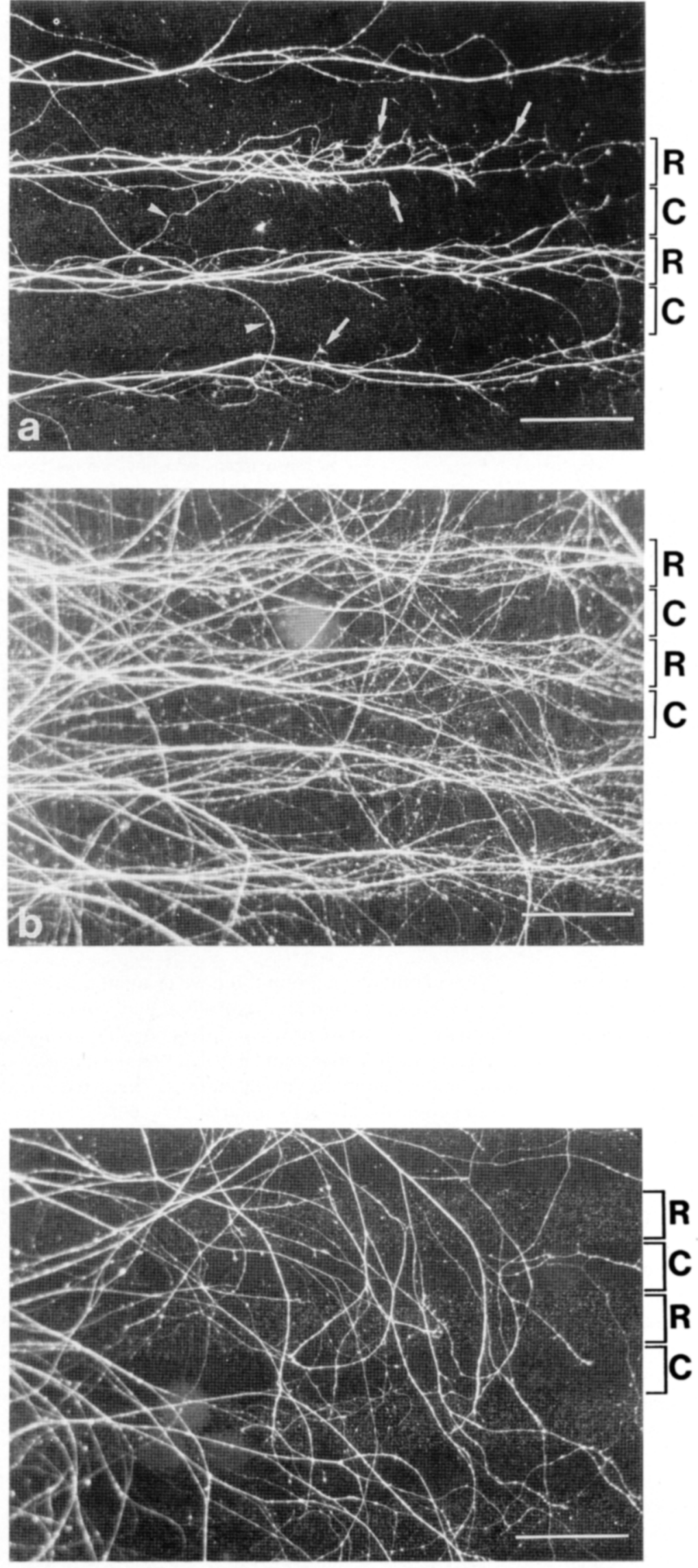

Figure 2. Photomicrograph of dil-Stained Axons from a Temporal Retinal Explant

The explants (not shown) are to the left Axons grew on membranes derived from rostral ( $R$ ) and caudal (C) tectum that were applied to a filter support in alternating stripes. The width of the stripes is indicated by brackets to the right. (a) Caudal membranes had been applied first, and rostral membranes second. Membranes from caudal tectum were mixed with fluorescent beads, which are discernible as white dots. The temporal axons extended preferentially on the unlabeled stripes containing rostral membranes. Arrowheads point to examples of temporal axons that cross over caudal membranes. Arrows indicate growth cones that contact the boundary between the stripes of rostral and caudal membranes. (b) Membranes from ros tral tectum (R) were applied first, and those from caudal tectum (C) second. Rostral membranes were mixed with fluorescent beads, which are visible as white dots. The temporal axons grow preferentially on rostral membranes; however, a substantial number of axons cross over rostral and caudal membranes. Bar, $200 \mu \mathrm{m}$.
Figure 3. Photomicrograph of dil-Stained $\mathrm{Na}$ sal Axons

Axons emerging from the explant to the left; not shown) randomly cross over the stripes of rostral and caudal membranes. Rostral membranes (mixed with fluorescent beads) were applied first and caudal membranes second. Bar, $200 \mu \mathrm{m}$. 
A

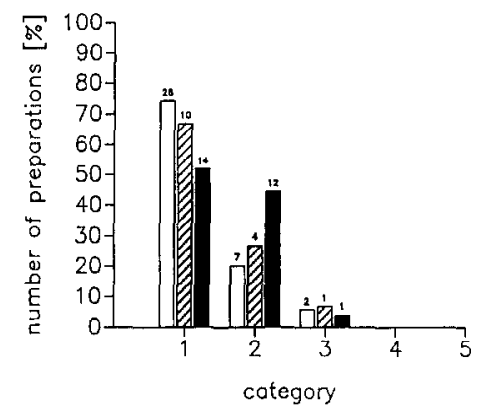

C nasal retino membrane application: $1 . C / 2 . R$

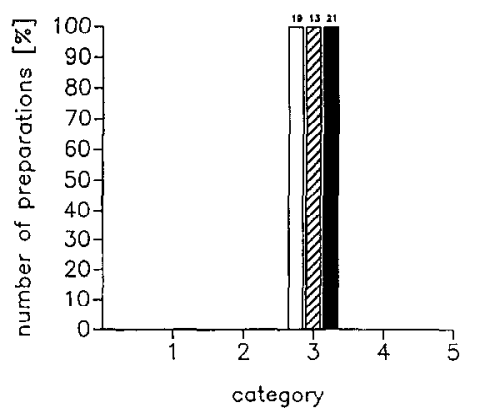

B
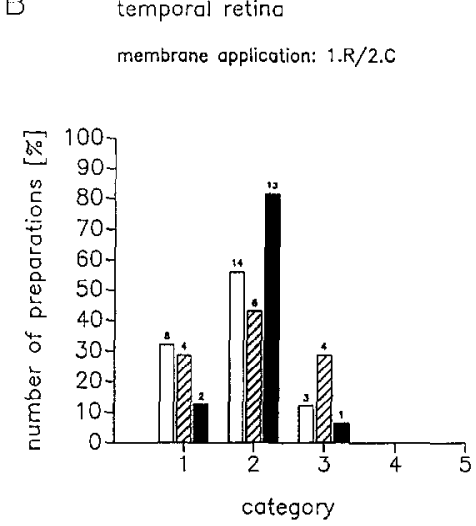

D

\section{nasal retino}

membrune application: $1 . R / 2 . C$

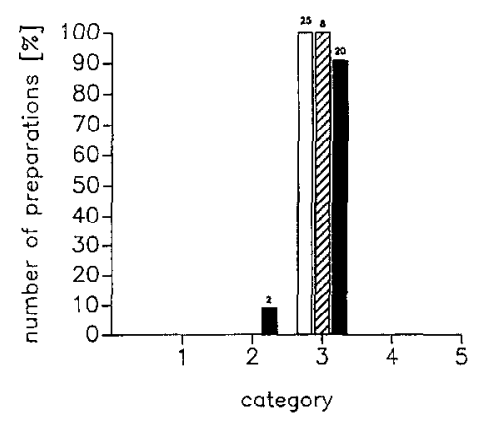

Гigure 4. I listograms Showing the Distribution of Preparations Falling into the Scoring Categories 1 to 5

For an explanation of categories see Results and Figure 5. Open bars indicate tectal mem branes derived from tecta of normal goldfish. Hatched bars indicate tectal membranes derived from tecta previously connected to optic nerves that had been cut 14-17 days prior to the preparation of the membranes. Black bars indicate tectal membranes from longterm denervated tecta. (A) and (B) give the scores for experiments in which the growing axons originated from temporal retinal explants; (C) and (D) give the scores for those originating from nasal explants. In experiments represented by $(A)$ and $(C)$, the caudal membranes were applied first and rostral membranes second (membranes: C/R). In experiments represented by (B) and (D), this order was reversed (membranes: $R / C$ ). Shown on top of each bar is the number of experimental cases. tions). Neither dorsal nor ventral axons accumulated on one of the stripes, but instead crossed over both types of membranes randomly. Thus, their behavior closely resembled that of nasal axons.

\section{Growth Behavior of Retinal Axons on Jectal Membranes Is Independent of the Previous Innervation of the Tectum}

To determine whether the preference of temporal axons for rostral membranes is dependent on the retinal innervation of the tectum, two additional sets of experiments (groups two and three) were carried out. In group two, membranes were prepared from tecta connected to optic nerves that had been sectioned 14-17 days prior to the isolation of the tecta. Membranes from normal tecta contain fragments of normal retinal afferents, whereas membranes from tecta at 14-17 days after optic nerve scction contain either no axons or debris of degenerating axons and fragments of a few regenerating axons (Stuermer and Easter, 1984a). The mode of growth of temporal and nasal axons on these membranes was similar to that on membranes of normal fish, as demonstrated in Figures 4A-4D (hatched bars).
In experiments of group three we examined whether the preference of temporal axons is at all influenced by fragments of normal or re- and degenerating axons by preparing membranes from tecta that had been deprived of retinal afferents for 10-12 months. These tecta had shrunken in thickness by roughly $30 \%-50 \%$ (Stuermer and Easter, 1984a) and gave two-thirds to one-half of the membrane material obtained from normal tecta. Electron microscopic examinations proved that retinal axon remnants were absent from these tecta (Bastmeyer and Sluermer, unpublished data). Again, we found that temporal axons preferred to grow on rostral membranes (Figures $4 \mathrm{~A}$ and $4 \mathrm{~B}$, black bars). Random growth was exhibited by nasal axons (Figures $4 \mathrm{C}$ and $4 \mathrm{D}$, black bars) with one exception. In one experiment axons from two nasal retinal explants on one filter exhibited a slight tendency to travel on rostral membranes. The reasons for this deviant bchavior, which was observed only once, are unclear.

\section{Quantification of Axonal Outgrowth on Rostral and Caudal Membranes}

The experiments of the preceding sections indicate, first, 

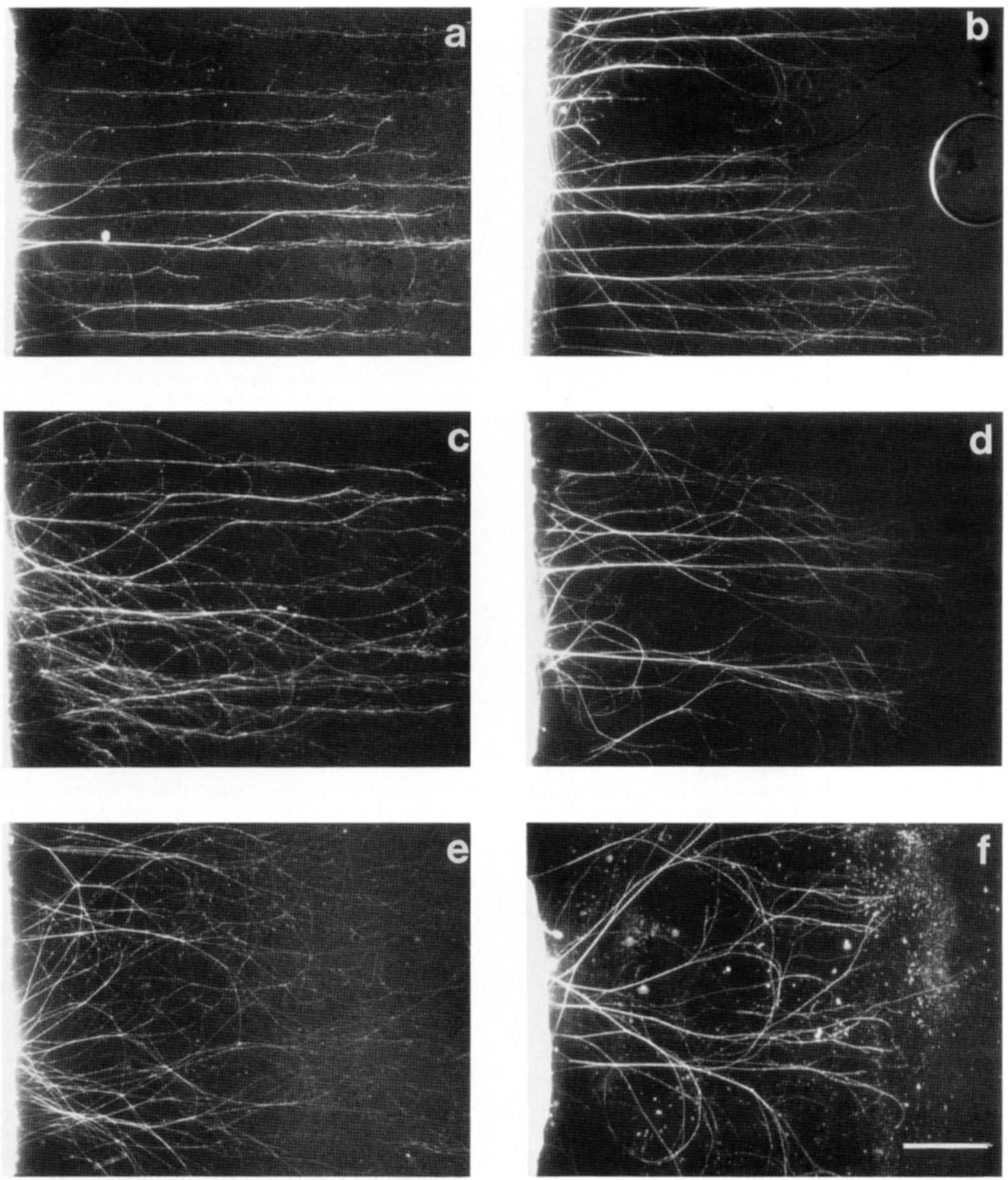

Figure 5. Photomicrographs at Low Magnification to Illustrate the Growth Patterns of Temporal Axons on Alternating Stripes of Rostral and Caudal Membranes

The retinal explants from which the axons emerged are to the left. To reproducc both the heavily fluorescent explant and the dil-stained axons in one picture, the fluorescence of the explant was partially excluded by closure of the aperture of a diaphragm. (a, $c$, and e) Temporal axons. Caudal membranes were applied first; rostral membranes second. (b, $d$, and $f$ ) Temporal axons. Rostral membranes were applied first: caudal membranes second. The growth patterns in (a) and (b) belong to categury 1 of the scoring scale (cumpare Results), those in (c) and (d) belong to to category 2 , and (e) and (f) exemplify category 3 .

Bar in (f) $500 \mu \mathrm{m}$; Magnification is the same in (a)-(c). 


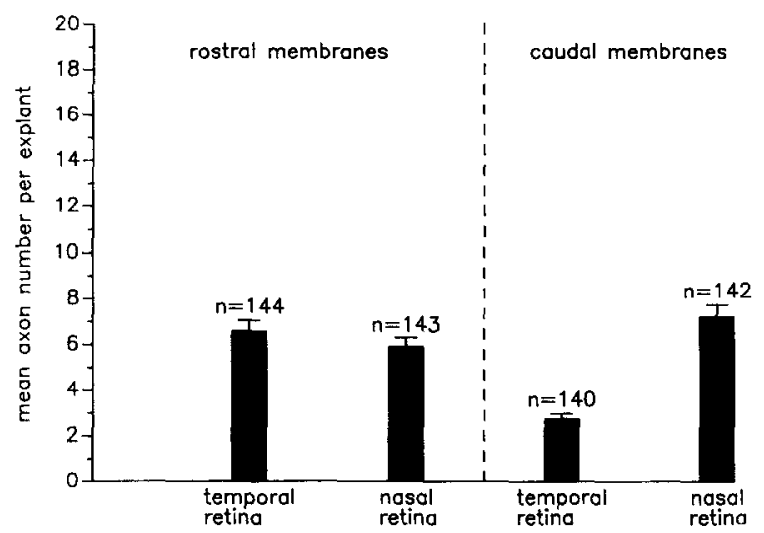

Figure 6. Histograms Showing the Number of Axons Emerging from Temporal and Nasal Retinal Explants on Rostral or Caudal Tectal Membranes.

that tectal cell surfaces possess components that promote the growth of regenerating retinal axons and, second, that growing temporal axons are sensitive and respond to a position-specific difference of the membranes. The question of whether differences between rostral and caudal membranes could also noticeably influence the outgrowth of the axons from the temporal and nasal explants was addressed in the next experiment. The number of axons emerging from more than 140 temporal and nasal retinal explants residing on either rostral or caudal membranes (see Experimental Procedures) was determined after $48 \mathrm{hr}$ in culture.

On rostral membranes the number of axons emerging from temporal and nasal explants was strikingly similar. This is documented in Figure 6 (left). The outgrowth of nasal axons on caudal membranes (Figure 6, right) was similar to that of temporal or nasal axons on rostral membranes. Significantly reduced, however, was the number of temporal axons on caudal membranes (Figure 6, right). Caudal membranes are obviously less permissive for the outgrowth of temporal axons than rostral membranes. These results suggest that the ganglion cells of the temporal retina are susceptible either to a component associated with caudal membranes that partially suppresses axonal outgrowth or to a difference in concentration of a growth-supporting component, which should be higher on rostral than on caudal membranes. As in the choice assay, nasal axons do not respond to these differences in membrane components.

\section{Discussion}

On a surface consisting of alternating stripes of membranes from rostral and caudal tectum, axons from temporal retina prefer to grow on membranes derived from their retinotopically appropriate rostral tectal half. Nasal axons lack this preference and grow randomly over the stripes.

The detection of this specific axonal behavior was made possible by a special in vitro assay developed by
F. Bonhoeffer (Walter et al., 1987a). This assay is presented and critically evaluated in a recent publication (Walter et al., 1987a). The preparation of the membranes from goldfish tecta and their application in stripes was in its major steps identical to the procedures described for chick in Walter et al. (1987a) and will therefore not be discussed here.

\section{Preferential Growth of Temporal Axons Involves a Specific Interaction with Tectal Cell Surface Components}

The preferential growth of temporal axons on rostral tectal membranes is not a result of their inability to extend on caudal membranes. This has been shown by control experiments. Axons from temporal relinal explants grow on caudal membranes when no choice is offered. Furthermore, temporal axons are able to leave their stripes of preference and cross over membranes of caudal tectal origin. Incidentally, this and the unrestricted random growth of nasal axons over alternating membrane stripes also rule out the possibility that growth in stripes is a result of mechanical restriction (Walter et al., 1987a).

Not the choice assay, but the quantification of axonal outgrowth from retinal miniexplants revealed that rostral and caudal tectal membranes differ in their ability to support axonal outgrowth from temporal explants. Judged by the number of axons emerging from the explants, rostral membranes support the outgrowth of nasal and temporal axons equally well. Outgrowth of axons from nasal retinal explants occurs on caudal membranes to the same extent as on rostral membranes. Axonal outgrowth of temporal axons, however, is considerably reduced on caudal membranes. This suggests that rostral and caudal membranes may possess more than one difference in cell surface components and that only the growth of temporal axons is affected by this difference. Whether this differential growth effect on temporal axons rests on a higher concentration of specific growth-promoting molecules on the rostral tectum or whether molecules on the caudal tectum specifically suppress the growth of temporal axons cannot be decided by these experiments. It is not even clear whether the components that induce temporal axons to accumulate on rostral membranes (when offered a choice between rostral and caudal membranes) and the components responsible for the reduced outgrowth rate on caudal membranes are the same. In any case both effects would be consistent with the idea that components associated with caudal membranes are affecting the growth of temporal axons.

If caudal membranes had specific properties that are sensed by temporal axons, the results of the choice assay would imply that temporal axons avoid elongation on caudal membranes and therefore elongate preferentially on rostral membranes. This speculation is consistent with the outcome of the experiments by Walter et al., $(1987 \mathrm{a}, 1987 \mathrm{~b})$ in the chick. These authors suggest that caudal membranes in the chick possess membrane-associated components that exert a repulsive influence on the temporal axons. Thus, in the choice assay, embryonic chick axons choose to grow on rostral membranes, 
since they are sensitive to and actively avoid the repulsive component associated with caudal membranes. This component of the chick can be inactivated by heat treatment of the caudal membranes (Walter et al. 1987b).

Whether the growth of temporal axons on rostral membranes in fish involves a repulsive influence of caudal membranes on temporal axons remains to be clarified. Heat treatments of caudal membranes that selectively destroyed the repulsive components of the chick caudal membranes (Walter et al., 1987b) were not successful in fish. Exposing the fish membranes to the same temperature $\left(63^{\circ} \mathrm{C}\right)$ had devastating effects in that the membranes obviously lost their general growth permissivity (unpublished data). The axons failed to elongate on these membranes. Temperatures up to $43^{\circ} \mathrm{C}$ had no noticeable effect: the temporal axons still segregated when confronted with rostral and heat-treated caudal membranes. Additional experiments are required to search for conditions that would affect the presumed repellant but not the growth supportiveness of the caudal membranes. Without direct evidence we cannot decide whether the specific behavior of temporal axons rests on their sensitivity to a repulsive component. However, based on the striking similarities between fish and chick, it is not unreasonable to assume that this may be the case. This then would be consistent with the finding that the preference of temporal axons for rostral membranes is weakened when the rostral membranes are contaminated by membranes of caudal tectal origin (Figure 2 b).

Temporal axons prefer rostral membranes, independent of whether they originate from normal tecta; tecta previously connected to regenerating nerves, or tecta deprived of retinal afferents for many months (long-term denervated tecta). These tests were necessary to rule out the possibility that the preference of axons would rest on a specific recognition of retinal axon fragments in tecta from which the membranes are derived. According to our results, the presence or absence of regenerating axons or their remnants in membrane preparations appears to be irrelevant for the growth behavior of temporal axons in vitro. This substantiates the notion that the membrane-associated guiding components are not on retinal axon fragments in tectum. Using tecta from embryonic chicks whose eyes had been removed prior to the arrival of retinal axons, Walter et al. (1987a) came to the same conclusion.

\section{Random Growth of Nasal Axons}

Nasal axons never exhibited a preference for one of the membrane stripes. The reason for this lack of preference is unknown. Evidence from in vivo work strongly suggests that nasal axons are also guided by positional markers on tectum (Stuermer, 1988a, 1988b, 1988c; Humphrey and Stuermer, 1988). Thus, either the nasal axons lose their sensitivity for specific membrane components in vitro, the relevant components are lost during the process of membrane preparation, or the components are not associated with cell membranes.
Using methods identical to those described above, dorsal and ventral axons also failed to differentiate between membranes derived from their appropriate ventral and dorsal hemitecta. The specific response of temporal axons in the choice assay and the absence of specific responses of nasal, dorsal, and ventral axons are similar in fish and chick (Walter et al., 1987a). Experiments are in progress to determine whether fish axons are sensitive to the membrane-associated tectal cell component of chick, and vice versa. This will provide information on whether the specific components relevant to temporal axons may be preserved in different species.

\section{Comparison between Embryonic Chick and Adult Goldfish}

Using the embryonic chick retinotectal system, Bonhoeffer and Huf (1982) and Walter et al. (1987a) were the first to demonstrate the preferential growth of temporal axons on rostral tectal cells or membranes and the lack of any preference of nasal axons in vitro. Thus, retinal axons from adult goldfish and embryonic chick ex hibit the same behavior when exposed to rostral and caudal tectal membranes in alternating stripes. In chick, retinal explants extend neurites best when they are derived from E6-E9 embryos, and the number of growing axons declines in explants of older embryos. Furthermore, chick retinal axons cease to show their preference when the membranes derive from tecta older than E14. This indicates that the specific membrane-associated components are absent from tecta after the time at which the establishment of the retinotectal map in vivo is close to completion (Crossland et al., 1975; McLoon, 1985). In goidfish, in contrast, the specific response of temporal axons persists on membranes of all ages. This is compelling in the light of the different characteristics of chick and fish development. Unlike chick, in fish both the retina and the tectum continue to grow throughout the life (Raymond and Easter, 1983). This implies that there is always a population of axons, originating from newly added ganglion cells, that has to seek out its retinotopic target sites in tectum.

Although mechanisms like specific axon-axon interaction (Cook and Horder, 1977) could theoretically mediate the home-finding of these axons, one is tempted to speculate that the tectal cell surface components are involved in the guidance of these axons. Thus, the permanent availability of the tectal guidance cues and the process of continuous map formation may be causally related. Perhaps even the fish's capacity to regenerate a retinotopic projection in tectum may rest on the continuous expression of the specific tectal cell surface component. Implicit in these speculations is the assumption that the specific response of temporal axons to surface components of tectal cells in vitro plays a role in the guidance of axons in vivo. Spatial marker molecules have been suggested to enable the growing axons to find their retinotopic target in tectum (for instance, Sperry, 1963; Gierer, 1981, 1987; Bonhoeffer and Gierer, 1984). The components responsible for the preference of tem- 
poral axons for rostral membranes may be one candidate of these hypothetical markers.

\section{Experimental Procedures}

\section{Preparation of Cell Membrane Fragments}

For each group of experiments, tectal hemispheres from 10 goldfish $(7-10 \mathrm{~cm}$ body length) were isolated, transferred into Leibovitz medium (CIBCO), and divided into rostral, middle, and caudal thirds. Rostral and caudal thirds were pooled separately and homogenized in $250 \mu \mathrm{l}$ of homogenization solution consisting of 10 $\mathrm{mM}$ Tris- $\mathrm{HCl}$ buffer ( $\mathrm{pH} 7.4), 1.5 \mathrm{mM} \mathrm{CaCl}, 1 \mathrm{mM}$ spermidine (Serva) (to stabilize the nuclei), the glucosidase inhibitor 2,3-dehydro-2-deoxy-N-acetylneuraminic acid (Sigmd), and the following protease inhibitors: aprotinine $(25 \mu \mathrm{g} / \mathrm{ml})$, leupeptine $(25 \mu \mathrm{g} / \mathrm{ml})$, and pepstatin $(5 \mu \mathrm{g} / \mathrm{ml})$. The homogenate was centrifuged for 10 min at $25000 \mathrm{rpm}$ in a sucrose step gradient (upper phase $50 \mu$ of $5 \%$ sucrose; lower phase $15 \mu \mathrm{l}$ of $50 \%$ sucrose) in a Beckman ultracentrifuge. The resulting interband was washed in $1 \mathrm{ml}$ of PBS and repelleted for $10 \mathrm{~min}$ at $4^{\circ} \mathrm{C}$ in Eppendorf reaction tubes in a Heraeus biofuge. After washing the pellet twice in PBS containing the same protease and glucosidase inhibitors as found in the homogenization buffer, it was resuspended in $1 \mathrm{ml}$ of PBS without inhibitors. The membrane concentration was determined by its optical density measured with a photospectrometer (Shimadzu) at $220 \mathrm{~nm}$. A $50 \mu \mathrm{l}$ sample of the membrane suspension was solubilized in 750 $\mu 1$ of PBS with $2 \%$ SDS to measure the actual protein concentration. The membrane suspension was either diluted or concentrated to the desired optical density of 0.1

\section{Preparation of Membrane Stripes}

Membrane stripes (Figure 1) were prepared according to Walter et al. (1987a). To generate alternating stripes of rostral and caudal membranes, a Nucleopore filter $(0.1 \mu \mathrm{m}$ pore diameter) was placed onto a special silicon matrix (Walter et al., 1987a). In its center, this matrix contains an area of parallel bars separated by channels. In contact with the filter, the bars protect the underlying filter pores in a striped pattern. The first membrane suspension $(150 \mu l)$ is applied to the filter, and by low pressure suction ( $2 \mathrm{~min}, 1.7$ Pascal) through the channels, the membrane particles attach to the filter in parallel stripes and subsequently occlude the pores in this region. The second membranes $(150 \mu \mathrm{l})$ are sucked to the filter $(1.5 \mathrm{~min}$, 1.9 Pascal) after replacing the silicon matrix by a nylon tissue. Suction is only effective through pores previously protected by the bars of the silicon matrix. The rostral membranes were applied first and the caudal membranes second, or this order was reversed. The membranes applied first were mixed with fluorescent beads to facilitate their identification.

\section{Retinal Explants and Culture Condition}

Between 14 and 17 days prior to isolation of the retinas, the fish's optic nerves were cut under MS-222 anesthesia, which conditions the ganglion cells to regenerate their axons (Landreth and Agranoff, 1979). Fish were dark adapted to facilitate removal of the pigment epithelium from the isolated retina. Prior to dissection, the extirpated eye was briefly washed in $96 \%$ ethanol and rinsed in Leibovitz medium. After removal of cornea, vitreous body, and pigment epithelium, the retina was attached (photoreceptor layer down) to a nylon filter (Hybond, Amersham).

\section{Staining of the Retinal Axons}

Rhodamine labels chick retinal cells and the neurites extending from explants of chick retina (Walter et al.,1987a), but it does nol adequately stain goldfish axons. An intense labeling of fish axons is achieved with the fluorescent dye dioctadecyl-3,3,3,3'tetramethyl-indocarbocyanine perchlorate (dil; Honig and Hume, 1986). In contrast to rhodamine, dil is insoluble in water. When brought into physical contact with ganglion cells, dit becomes incorporated into cells and is transferred to the growing end of the elongating axons (Schwartz and Agranoif, 1981; Honig and Hume, 1986; Vielmetter, 1986; Thanos and Bonhoeffer, 1987; Stuermer, 1988c). To make the dye accessible to all or most of the retinal cells, we found it necessary to remove the vitreous body and blood vessels overly- ing the fish retina and the axons of the ganglion cell layer. To stain the retina, the following suspension was prepared: $1 \mathrm{mg}$ of dil (Molecular Probes) was dissolved in $100 \mu \mathrm{l}$ of ethanol, and this solution was suspended in $10 \mathrm{ml}$ of Leibovitz medium. After a $1 \mathrm{hr}$ centrifugation in a Heraeus minifuge at $6000 \mathrm{rpm}$ and $10^{\circ} \mathrm{C}$, the supernatant was discarded and the dil pellet was suspended in $3 \mathrm{ml}$ of Leibovitz medium. The exposed ganglion cell layer was covered with the dil suspension, and the retina was centrifuged for $10 \mathrm{~min}$ at $1500 \times \mathrm{g}$ and $10^{\circ} \mathrm{C}$ with the Titertec-plate-rotor of the Heraeus minifuge. To remove the superfluous dil surrounding the retina, the retina was removed from the filter and attached to a new filter. To judge the proportion of dil-labeled and unlabeled axons, stained retinal explants were grown on coverslips coated with laminin and sequentially viewed with phase-contrast and under fluorescent light (Vielmetter, 1986). This comparison revealed that at least $95 \%$ of all axons were stained with dil.

The retina was trimmed, and dorsal and ventral segments were discarded, resulting in the shape shown in Figure 1. Filter and retina were cut into $300 \mu \mathrm{m}$ wide segments with a Mcllwain Tissue Chopper. The segments were placed (ganglion cell layer down) onto the tectal membranes (see above) in an orientation perpendicular to the membrane stripes and kept in a plastic petri dish $13.5 \mathrm{~cm}$ in diameter). To keep the retina in contact with the substrate during the addition of the culture medium, small metal blocks were placed onto the ends of the filter to which the retina was attached. Three milliliters of modified Leibovitz medium (Johnson and Turner, 1982) supplemented with $10 \%$ fetal calf serum (GIBCO), $4 \%$ methyl cellulose (DOW), and $50 \mathrm{mg} / \mathrm{l}$ gentamycin (GIBCO) was added to the culture, which then was incubated at $23^{\circ} \mathrm{C}$ in a humidified cham. ber. After 3 days in culture, the preparations were fixed overnight with 4\% paraformaldehyde in PBS containing $11.6 \%$ sucrose, embedded in 25\% Mowiol (Hoechst) in PBS, covered with a coverslip. and viewed with a rhodamine or fluorescein filter set under a fluorescence microscope (Axiophot, Zeiss).

\section{Quantitative Growth Assay}

To decide whether caudal and rostral membranes differ in their ability to support axonal outgrowth, membranes of rostral and cau dal tectum (prepared as described above) were centrifuged down to the bottom of wells of 96 -well dishes (NUNC). Small retinal explants $(200 \times 200 \mu \mathrm{m})$ of defined positional origin were distributed systematically over the wells such that $50 \%$ of the wells with rostral membranes and $50 \%$ of the wells with caudal membranes received temporal miniexplants. The other $50 \%$ of the wells with rostral or caudal membranes obtained nasal miniexplants. After $48 \mathrm{hr}$ in culture, the number of axons per explant was determined. When axons formed fascicles they usually did so only over parts of their paths. The number of axons contributing to a fascicle was determined either before the axons merged or after they diverged again. On rare occasions, in which axons appeared tightly fasciculated throughout their paths, the fascicle was counted as a single axon. This procedure implies some imprecision in axon counts. However the counting errors are similar in all experiments, since - in contrast to chick (Walter et al., 1987a) - the degree to which fish axons fasciculate does obviously not depend on their positional origin or on the origin of the membranes. Within each of the four experimental groups, the number of axons of all explants was pooled.

\section{Acknowledgments}

We wish to thank $F$. Bonhoeffer for introducing us to and for providing us generously with the test assay. We thank D. D. M. O'Leary and $\mathrm{S}$. Korsching for critically reading the manuscript. The experiments were performed with the excellent technical assistance of Marianne Wiechers.

Received December 28, 1988; revised February 10, 1989.

\section{References}

Bonhoeffer, $F_{1}$, and Huf, J. (1982). In vitro experiments on axon guidance demonstrating an anterior-posterior gradient on the tectum. EMBO J. 1, 427-431. 
Bonhoeffer, F., and Gierer, A. (1984). How do retinal axons find their targets on the tectum? Trends Neurosci. 7, 378-381.

Cook, 1. E., and Horder, T. J. (1977). The multiple factors determining retinotopic order in the growth of optic fibres into the optic tectum. Phil. Trans. Roy. Soc. (Lond.) B 278, 261-276.

Crossland, W. I., Cowan, W. M., Rogers, L. A., and Kelly, J. P. (1975). Specification of the retino-tectal projection in the chick. J. Comp. Neurol. 155, 127-164.

Fujisawa, H. (1987). Mode of growth of retinal axons within the tectum of Xenopus tadpoles, and implications in the ordered neuronal connection between the retina and tectum. J. Comp. Neurol. 260. 127-139.

Fujisawa, H., Tani, N., Watanabe, K., and Ibata, Y. (1982). Branch ing of regenerating retinal axons and prefcrential selection of ap propriate branches for specific neuronal connection in the newt Dev. Biol. 90, 43-57.

Gaze, R. M. (1970). The Formation of Nerve Connections (London: Academic Press, Inc.)

Gierer, A. (1981). Development of projections between areas of the nervous system. Biol. Cybern, 42, 69-78

Gierer, A. (1987). Directional cues for growing axons forming the retinotectal projection. Development 101, 479-489.

Harris, W. A. (1984). Axonal pathfinding in the absence of normal pathways and impulse activity. J. Neurosci. 4, 1153-1162.

Holt, C. E., and Harris, W. A. (1983). Order in the initial retinotectal map in Xenopus: a new technique for labelling growing nerve fibers. Nature 301, 150-152.

Honig, M. G., and Hume, R. J. (1986). Fluorescent carbocyanine dyes allow living neurons of identified origin to be studied in longterm cultures. J. Cell Biol. 103, 171-187.

Humphrey, M. F., and Stuermer, C. A. O. (1988). Tectal pathways of regenerating goldfish optic axons after half-nasal or half-tempora! retinal removal. Development 102, 479-488.

Johnson, 1. E., and Turner, J. E. (1982). Growth from regenerating retinal cultures in the absence of serum or hormonal supplements tissue extract effects. J. Neurosci. Res. 8, 315-329

Kern-Veits, B. (1985). Untersuchungen zur spezifischen Erkennung von Oberflächenkomponenten in Zellmembranen durch retinale Axone in vitro. Ph.D. thesis, University Tübingen, Tübingen, FRG. Landreth, G. E., and Agranoff, B. W. (1979). Explant culture of adult goldfish retina: a model for the study of CNS regeneration. Brain Res. 161, 39-53.

McLoon, S. C. (1985). Evidence for shifting connections during development of the chick retinotectal projection. I. Neurosci. 5 . $2570-2580$.

Meyer, R. L., Sakurai, K., and Schauwecker, E. (1985). Topography of regenerating optic fibers in goldfish traced with local wheat germ injections into retina: evidence for discontinuous microtopography in the retinotectal projection. I. Comp. Neurol. 239, 27-43.

Murray. M. (1976). Regeneration of retinal axons in the goldfish optic tectum. J. Comp. Neurol. 168, 175-196

Purves, D., and Lichtman, J. W. (1985). Principles of Neural Devel opment (Sunderland, MA: Sinauer Associates)

Raymond, P., and Easter, S. S. (1983). Postembryonic growth of the optic tectum in goldfish. J. Neurosci. 3, 1077-1091.

Schwartz, M., and Agranoff, B. W. (1981). Outgrowth and maintenance of neurites from cultured goldfish retinal ganglion cells. Brain Res. 206, 331-343

Sperry, R. W. (1963). Chemoaffinity in the orderly growth of nerve fiber patterns and connections. Proc. Natl. Acad. Sci. USA 50. 703-709.

Stuermer, C. A. O. (1988a). The trajectories of regenerating retinal axons in the goldfish. I. A comparison of normal and regenerated axons at late regeneration stages. J. Comp. Neurol. 267, 55-68.

Stuermer, C. A. O. (1988b). The trajectories of regenerating retinal axons in the goldfish tectum. II. Exploratory branches and growth cones on axons at early regeneration stages. I. Comp. Neurol. 267. $69-91$.
Stuermer, C. A. O. (1988c). Retinotopic organization of the de veloping retinotectal projection in the zebrafish embryo. I. Neurosci. 8, 4513-4530.

Stuermer, C. A. O. (1988d). Path- and homefinding of regenerating retinal axons in goldfish. In Post-Lesion Neural Plasticity, H. Flohr ed. (Berlin: Springer-Verlag), pp. 489-497.

Stuermer, C. A. O., and Easter, S. S. (1984a). A comparison of the normal and regenerated retinotectal pathways of goldfish. J. Comp. Neurol. 223, 57-76

Stuermer, C. A. O., and Easter, S. S. (1984b). Rules of order in the retinotectal fascicles of goldfish. I. Neurosci. 4, 1045-1051.

Thanos, S., and Bonhoeffer, F. (1987). Axonal arborization in the developing chick retinotectal system. I. Comp. Neurol. 261, 155-164. Vielmetter, 1. (1986). Auswachsen und Verhalten retinaler Ganglienzellaxone des Goldfisches in vitro. Diploma thesis, University Tübingen, FRG

Walter, 1., Kern-Veits, B., Huf, J., Stolze, B., and Bonhoeffer, F. (1987a). Recognition of position-specific properties of tectal cell membranes by retinal axons in vitro. Development 101, 685-696. Walter, J., Henke-Fahle, S., and Bonhoeffer, F. (1987b). Avoidance of posterior tectal membranes by temporal retinal axons. Development 101, 909-913. 